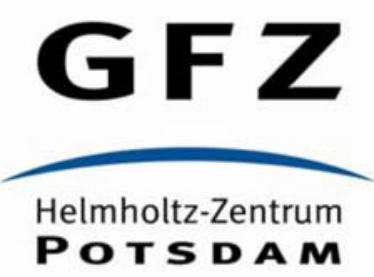

Originally published as:

Frings, P. (2019): Palaeoweathering: How Do Weathering Rates Vary with Climate? Elements, 15, 4, pp. 259-265.

DOI: http://doi.org/10.2138/gselements.15.4.259 


\title{
Palaeoweathering: How Do Weathering Rates Vary with Climate?
}

Patrick J. Frings ${ }^{1,2}$

\begin{abstract}
A feedback between Earth surface weathering and climate is thought to be fundamental in maintaining Earth's habitability over long timescales, but investigating this control in the modern world is difficult. The geologic record of cycles between glacial and interglacial conditions of the last 2.6 million years allows us to study weathering feedback in action. A suite of mineral, element and isotope proxies has been applied to address how weathering rates have varied over glacial cycles. Despite evidence for substantial local changes, the emerging answer at a global scale seems to be, "not very much".
\end{abstract}

Keywords: silicate weathering, glacial-interglacial cycles, long-term carbon cycle, metal stable isotopes, radiogenic isotopes, cosmogenic nuclides

\section{INTRODUCTION}

The oceans, atmosphere and biosphere together contain about $3 \times 10^{18} \mathrm{~mol}$ of carbon, the majority of which is in the ocean. There is a continuous input into this pool of about $10 \times 10^{12} \mathrm{~mol} \mathrm{C} \mathrm{y}^{-1}$ from mid-ocean ridges, volcanoes and other sources, collectively termed "solid Earth degassing," which is dwarfed by the fluxes of carbon between the different reservoirs of the Earth surface. For example, the transfer of carbon from atmosphere to biosphere via photosynthesis is about $10 \times 10^{15} \mathrm{~mol} \mathrm{C} \mathrm{y}^{-1}$, meaning we can justifiably ignore solid Earth degassing in models of climate change on human timescales. Yet, there must be a carbon sink that counteracts solid Earth degassing, otherwise carbon would gradually accumulate at the Earth's surface over long-timescales. Because the rate of degassing has varied over Earth history, the sink must also be somehow related to the size of the surficial carbon pool via a negative feedback mechanism (FIG. 1). Because $\mathrm{CO}_{2}$ is an important greenhouse gas, the feedback most likely operates via the climate system, of which the best understood

\footnotetext{
${ }^{1}$ Earth Surface Geochemistry

GFZ German Research Centre for Geosciences

Telegrafenberg, 14473 Potsdam, Germany

E-mail: patrick.frings@gfz-potsdam.de

2 Department of Geosciences

Swedish Museum of Natural History

Frescativägen 40, 10405 Stockholm, Sweden
} 
mechanism is silicate weathering (Walker et al. 1981). Central to this feedback is a climatic control on weathering reactions that have the net effect of removing carbon from the Earth's surface. Briefly, the hydrolysis of silicate minerals converts atmospheric carbon to riverine bicarbonate $\left(\mathrm{HCO}_{3}^{-}\right)$. This bicarbonate can subsequently precipitate as carbonate minerals in the ocean, removing carbon from the Earth's surface (FIG. 1) (see Kasting 2019 this issue). Weathering also supplies nutrients to the ocean, increasing the efficiency of the biological pump and organic carbon burial.

On our solar system neighbours, any silicate-weathering feedback on atmospheric $\mathrm{CO}_{2}$ levels apparently either failed or never existed. On Earth, there have been billions of years of habitable temperatures, requiring a tight balance between carbon sources and sinks over these timescales (FIG. 2). Zeebe and Caldeira (2008) presented direct evidence for a close mass balance of surface carbon on shorter timescales, based on $\mathrm{CO}_{2}$ concentrations in gas bubbles trapped in ice cores combined with records of ocean chemistry. They concluded that there has been essentially no long-term trend in atmospheric $p \mathrm{CO}_{2}$ over the last $610 \mathrm{ky}$, with any net imbalance between carbon inputs to and outputs from the surface environment confined to less than $1 \%-2 \%$. In other words, both theoretical and empirical considerations suggest that the global carbon budget must be almost identically balanced over million-year timescales.

The silicate weathering feedback requires a climatic control on terrestrial weathering rates. Seafloor weathering may also be part of the story, though its dependence on climate is less obvious (see Kasting 2019 this issue). On land, warmer and wetter climates should produce greater weathering fluxes than cooler and drier climates. This prediction is generally borne out at local to global scales (e.g., Gaillardet et al. 1999), but the exact nature of the climate-weathering relationship is hard to define because other factors, independent of climate, can obscure any link. High rates of tectonic uplift, for example, translate into rapid physical erosion, which supplies reactive mineral surfaces for weathering. The converse is also true: slow uplift rates can lead to the development of thick regolith cover, effectively isolating bedrock and drastically lowering weathering rates. Different lithologies have sufficiently different reactivities such that bedrock heterogeneity might mask any climatic influence over weathering. Biological processes dominate the production of acidity and soil $p \mathrm{CO}_{2}$ - the driving forces for the silicate mineral hydrolysis reactions - but may vary in ways that are not simple to link to climate (see Porder 2019 this issue). There may also be long lag times as climate changes propagate through soil and regolith. Overall, it is not at all clear how efficiently the silicate weathering 
feedback acts as a planetary thermostat, nor what regulates the regulator. These are fundamental questions about a feedback that is central to how we think about the Earth system.

\section{USING THE PAST TO EXPLORE THE PRESENT}

Examining how weathering changed in response to past climate change can show how the feedback actually works through the combined effects of climate, biology and geomorphology. A useful starting point is to identify the timescales over which the feedback is important (FIG. 2). FIGURE 2 shows how atmospheric $\mathrm{CO}_{2}$ would evolve if the rates of carbon removal through weathering and carbon input from the solid Earth differ. Because weathering fluxes are so small relative to the fluxes between various compartments at the Earth's surface, even imbalances of $\pm 100 \%$ between degassing and weathering would have little effect on atmospheric $\mathrm{CO}_{2}$ on decadal to centennial timescales (FIG. 2B), though interactions with organic carbon burial might occur more quickly. Conversely, on million-year timescales, even tiny imbalances would be unsustainable and lead to a runaway greenhouse or icehouse (Berner and Caldeira 1997) (FIGS. 2C, 2D). The deviation of most $\mathrm{CO}_{2}$ reconstructions from a perfect balance (i.e., a flat line) reflects a different balance being established at different baseline conditions, and the small transient imbalances that occur as the Earth moves between them. Indeed, we are currently experiencing an imbalance - of approximately two orders of magnitude! - between degassing and weathering due to burning of fossil fuel pumping $\mathrm{CO}_{2}$ into the atmosphere (FIG. 2A). A smaller imbalance in the other direction is thought to be the mechanism by which the planet will eventually recover.

The Quaternary - the last 2.6 million years - has been characterised by swings between glacial and interglacial periods, with each cycle lasting $10^{4}-10^{5}$ years. Partitioning of carbon between ocean, atmosphere and biosphere varies drastically over glacial-interglacial (G-IG) cycles. The resulting swings in atmospheric $\mathrm{CO}_{2}$ and climate are particularly instructive for learning how the weathering feedback works. The positions of the continents and mountain belts that control ocean and atmospheric circulation do not differ between glacials and interglacials. Glacial-interglacial cycles are recent enough that high-resolution sediment archives are easily accessible, and the timescales of change are short enough that weathering itself could not have driven them (FIG. 2B). Yet they are also long enough that most of the confounding feedbacks have kicked in. In short, G-IG cycles represent one of the best possible "natural experiments" of how climate change influences weathering rates, an issue that cannot easily be investigated under modern conditions alone. Doing so will not only help us 
better understand the silicate-weathering feedback. It will also improve our understanding of the geochemical proxies, tighten constraints on how weathering rates will change in the future, and may even shine light on how we can speed up the weathering process to our benefit (Andrews and Taylor 2019 this issue).

\section{RECONSTRUCTING WEATHERING IN A GLACIAL WORLD}

The world during the last glacial maximum (about $21 \mathrm{ka}$ BP) was radically different from today (FIG. 3). Ice sheets several kilometres thick covered large parts of the northern hemisphere, sea levels were $130 \mathrm{~m}$ lower and ecosystems expanded and contracted latitudinally and altitudinally. Ice cores from both poles tell us that atmospheric $p \mathrm{CO}_{2}$ was 180 ppmv (parts per million by volume), about $50 \%$ lower than late Holocene levels. A suite of palaeoclimate proxies in ocean, lake and peatland sediments confirm that the world was cooler and drier in glacial times relative to today. Based on the activation energies typical of mineral weathering reactions, a $5{ }^{\circ} \mathrm{C}$ cooling corresponds to a reaction rate constant decrease of about 50\%. Water availability also drives chemical weathering reactions (Maher and Chamberlain 2014), so overall one might expect that global weathering rates were lower during glacial periods. On the other hand, the exposure of continental shelves (including weatherable shales) to subaerial weathering, or the production of finely ground and highly reactive subglacial sediment, might have counteracted the impacts of a cooler and drier climate.

The following sections summarise different approaches to the question, "How different are weathering rates in an ice-age world?" Because the past world is not directly accessible to measurement, we must use proxies to reconstruct the parameters of interest. A characteristic of silicate weathering is that the process tends to be incomplete, producing both solutes and secondary minerals (mostly clays and oxides). This means that there are two broad classes of palaeoweathering proxies in sedimentary archives: (1) Those that are based on the residual solids; (2) Those that are based on something that later precipitates from the solutes after they arrive and mix in the ocean. The principle that underpins the use of residual solids is clear: they were produced directly during the weathering process and so give insight into weathering in the region that produced them. Using something that was produced from seawater solutes, whether biological (e.g., siliceous diatoms, calcareous foraminifera, or organic matter) or inorganic (e.g., ferromanganese coatings), is slightly less direct. The central premise is that the different inputs to the ocean have distinct compositions, so a change in ocean composition through time reflects either a 
changing balance between the various inputs, or changing composition of the inputs, or both. The challenge is to work out which. These two types of proxies (residual solids vs. newly formed precipitates) complement one another: The former tends to offer local but highly time-resolved signals; the latter offers poorly time-resolved signals but at ocean basin to global scales. Many proxies mineralogical, elemental, and isotopic - have been developed, each with advantages and disadvantages. There is no perfect proxy, but are there any general lessons that can be drawn?

\section{MINERALOGICAL AND ELEMENTAL WEATHERING PROXIES}

The mineralogy of clays produced during silicate weathering depends on the climate (Biscaye 1965). Kaolinite, for example, is a clay mineral with the chemical composition $\mathrm{Al}_{2} \mathrm{Si}_{2} \mathrm{O}_{5}(\mathrm{OH})_{4}$ and is completely devoid of alkali and alkaliearth metal cations. Smectites, conversely, are groups of clay minerals that can contain substantial amounts of alkalis and alkali earths, particularly $\mathrm{Mg}$, $\mathrm{Ca}$, or $\mathrm{K}$. An abundance of kaolinite, therefore, tells us it was produced in a high-intensity weathering regime, where all soluble cations are completely leached. Here, weathering intensity refers to the fraction of total denudation accomplished chemically. A clay mineral assemblage dominated by smectites tells us the weathering regime that produced them was low-intensity, with less complete leaching. For example, Alizai et al. (2012) interpret their Indus River Delta clay mineralogy records as reflecting more intense weathering during the early Holocene than today, which they related to a strengthened summer monsoon. Zhao et al. (2018) and Wan et al. (2017) observe a higher kaolinite and a lower smectite abundance, respectively, in glacial-age sediments than in core-top sediments of the upper and lower South China Sea shelf. This may reflect more intense silicate weathering during glacial periods (FIGS. 4A, 4B). These records are largely qualitative and potentially sensitive to water circulation changes that could deliver sediment from different sources, but overall suggest the timing, magnitude and even direction of the terrestrial weathering response to deglacial climate change varies from location to location.

Taking a more geochemical approach, perhaps the simplest way to quantify palaeoweathering is to compare the composition of sediments with the rocks from which they were derived. One nuance is that sediment composition is largely grain size and density dependent - the finer grain sizes tend to be cationpoor clay minerals, while the larger grain sizes may contain unaltered and cation-rich primary rock fragments. This means that even subtle changes in depositional environment or the hydrodynamics of sediment transport can cause large changes in sediment geochemistry that need to be carefully accounted for. 
Nevertheless, it is a powerful approach. For example, both Bayon et al. (2012) and Lupker et al. (2013) have shown that concentrations of potassium, a soluble element readily lost during weathering, have decreased in detrital sediments since peak glacial time in the Congo River Delta and in the Bay of Bengal, implying more complete weathering in the warmer interglacial periods (FIGS. 4C, 4D).

One complicating factor is it is tricky to convert clay mineralogy or sediment geochemistry into a weathering rate. This requires knowing the rate at which sediment is exported from a catchment. In practice, this is rarely well known in the past. Changes in sedimentation rates, especially in near-shore locations, can vary drastically due to local hydrodynamics, especially in response to the sealevel fluctuations that characterise G-IG cycles. On top of this, there is still considerable debate about the ability of detrital sediments to change sufficiently quickly. Put simply, it takes time for sediment to follow the entire source-to-sink pathway, from bedrock via regolith and soil, to river sediment (with potential floodplain storage), to deposition in the marine realm. Soil profiles can have residence times of $>10^{5}$ years, and floodplain sediments perhaps even more. We might, therefore, expect that G-IG cycles recorded in a weathering proxy are strongly dampened and lagged. Given this, Thiry (2000) and others have warned that the erosion of relict soils can be particularly misleading, though this is less likely to be a problem in rapidly eroding settings.

Despite these issues, the geochemical data of Bayon et al. (2012) and Lupker et al. (2013), and many clay mineralogy records (e.g., Alizai et al. 2012; Zhao et al. 2018), do appear to vary near synchronously with the climate changes inferred to drive them. One reason may be that finer grains transit the floodplains of large rivers much quicker than bulk sediment. Another might be that the measured signals are in fact strongly buffered by catchment storage, relative to 'instantaneous' sediment being produced at a given time - and only a dampened signal is being measured. How we invert sedimentary records is a topic that deserves further attention.

\section{ISOTOPIC WEATHERING PROXIES}

One particularly useful class of proxies is based on stable isotope geochemistry. In general, these work by exploiting the changes in isotope ratios (a process termed "fractionation") that occur during silicate mineral weathering reactions. For many metals that have two or more stable isotopes, there is a fractionation between the secondary clay or oxide and the solute. This occurs because of the slightly different reaction kinetics of the isotopes, or because of chemical 
bonding environments in the mineral and solution that favour one isotope over another (Bouchez et al. 2013). The upshot is that the isotope ratios in both the secondary mineral and the solute should reflect how much of a given element from the primary mineral is retained in the secondary phase. This can be quantified from isotope ratios alone if the fractionation is known. If all the element is incorporated into one or the other phase, then mass-balance dictates that it must have the same isotope ratio as the source material. In intermediate cases, the isotope ratios of the secondary phases and the solutes will be a function of the partitioning of the element between the solute and the secondary phase.

The basic interpretation of many metal stable-isotope systems is thus that they trace the (element-specific) net reaction stoichiometry. The observation that underpins their use as a weathering proxy is that the net reaction stoichiometry varies with weathering intensity. Taking lithium as an example, data from a range of global rivers show that there is a pattern to the ${ }^{7} \mathrm{Li} /{ }^{6} \mathrm{Li}$ isotope ratios (expressed as $\delta^{7} \mathrm{Li}$ ) in dissolved Li (Dellinger et al. 2015). Low $\delta^{7} \mathrm{Li}$ occurs at very high weathering intensities (e.g., swampy lowland tropical rivers), and at very low weathering intensities (e.g., rapidly eroding mountainous streams) because the secondary clays are either dissolving themselves, or never form in the first place. Higher $\delta^{7} \mathrm{Li}$ values produced at intermediate weathering intensities reflects the partitioning of most weathered Li into secondary clays, and so the fractionation between dissolved $\mathrm{Li}$ and $\mathrm{Li}$ in secondary clays can be expressed.

This implies that both the secondary solid and the solutes contain complementary information, and that different elements have different sensitivities, though this is only just beginning to be exploited. Stable-isotope ratios of the rock-forming elements (e.g., $\mathrm{Si}, \mathrm{Ca}, \mathrm{Mg}$ or $\mathrm{Fe}$, and the trace elements $\mathrm{Li}$ and $\mathrm{Ge}$, among others) in river water therefore integrate net weathering reaction stochiometries over the whole catchment. One key advantage is that the isotope ratios of parent material often don't differ greatly between silicate lithologies (though mixing between silicate and carbonate rocks complicates interpretation of $\mathrm{Mg}$ or Ca isotopes). The solutes have no grain-size dependence, but there are other snags instead. It turns out that the fractionations between the secondary solid and the solute are variable in nature, and biological cycling can overprint inorganic fractionation. Despite this, stable isotope ratios in river solutes and sediments have been successfully linked to catchment weathering style (e.g., Bouchez et al. 2013; Dellinger et al. 2015; Frings et al. 2016). 
Lithium is perhaps the most exploited element. It is hosted almost exclusively in silicate rocks and has a negligible biological cycle, two characteristics that simplify interpretation. Lithium isotopes in foraminifera tests (generally considered to reflect the seawater ratio) have been used to infer a global decrease in weathering intensities over the last $50 \mathrm{Ma}$. Unfortunately, seawater $\delta^{7} \mathrm{Li}$ is insensitive on G-IG timescales because it is buffered by the $\sim 2 \mathrm{Ma}$ residence time of $\mathrm{Li}$ in the ocean. Indeed, Roberts et al. (2018) have recently shown that South Pacific foraminiferal $\delta^{7} \mathrm{Li}$ is nearly constant on G-IG timescales, with small variations due to changes in the fractionation associated with incorporation into calcite. Nevertheless, Li isotopes have found utility in phases precipitated from more local systems, a good example of the trade-off between spatial and temporal resolution. Pogge von Strandmann et al. (2017) showed that $\delta^{7} \mathrm{Li}$ in an Israeli stalagmite varied by more than $13 \%$ over the last deglaciation - about $50 \%$ of the total range in modern river waters (FIG. 4E). Similarly, the clay fraction of a Himalayan River terrace (Dosseto et al. 2015) and that of the Nile River Delta (Bastian et al. 2017) varies by about 6\%o over the same period (FIG. 4F). The implication is that there have been changes in the net weathering stoichometries in these regions over the past $20 \mathrm{ka}$ or so. Within the stoichiometry-intensity framework described above, this implies changes in the fraction of total denudation achieved chemically in these three catchments. The three records all have different absolute $\delta^{7} \mathrm{Li}$ values, which is expected given they reflect very different environments. More interestingly, they trend in different directions. Both the stalagmite and the Nile River Delta $\delta^{7} \mathrm{Li}$ values have decreased since peak glacial times (i.e., less Li incorporated into clays), while the Himalayan terrace record broadly increases from glacial to modern times. As with the clay mineralogical records, these suggest geographically variable weathering responses to G-IG climate change.

\section{Radiogenic Isotope Geochemical Tools}

A radiogenic isotope system refers to an element where one or more of the isotopes is the daughter isotope of a radioactively decaying parent isotope. For example, ${ }^{87} \mathrm{Rb}$ decays to ${ }^{87} \mathrm{Sr}$, or ${ }^{147} \mathrm{Sm}$ decays to ${ }^{143} \mathrm{Nd}$, meaning the ratio of the daughter to a non-radiogenic isotope of the same element (e.g., ${ }^{87} \mathrm{Sr} /{ }^{86} \mathrm{Sr}$, or ${ }^{147} \mathrm{Nd} /{ }^{144} \mathrm{Nd}$ ) varies through time. The build-up of the daughter isotope through radioactive decay of a parent typically results in ranges of isotope ratios much larger than the stable isotope variations that arise from mass-dependent fractionation.

As with the stable isotope systems above, the premise is that ocean isotope ratios reflect the weighted balance of the various inputs. For the case of 
strontium, hydrothermal exchange at mid-ocean ridges provides $\mathrm{Sr}$ with unradiogenic ${ }^{87} \mathrm{Sr} /{ }^{86} \mathrm{Sr}$ ratios of about 0.703 , while the global river average is higher, at around 0.712 (Mokadem et al. 2015). If the continental weathering flux were to increase while maintaining a constant ${ }^{87} \mathrm{Sr} /{ }^{86} \mathrm{Sr}$ ratio, then the ocean isotope ratio should increase towards the continental end member. Highly precise measurements of the ${ }^{87} \mathrm{Sr} /{ }^{86} \mathrm{Sr}$ ratio of seawater over the last $40 \mathrm{ka}$, recorded in foraminifera from Indian Ocean sediments, are identical within uncertainty (Mokadem et al. 2015) (FIG. 4H). The face-value interpretation is that any change in continental weathering flux must be very small. Exactly how small is based on how much variability is permissible given measurement uncertainties and the long residence time of $\mathrm{Sr}$ in the ocean. To put it another way, weathering changes below a certain magnitude would indiscernible in $\mathrm{Sr}$ isotope ratios (Mokadem et al. 2015).

In this case, although the long residence time of $\mathrm{Sr}$ limits the resolution, it is also an advantage: it means that $\mathrm{Sr}$ is well mixed (with homogenous ${ }^{87} \mathrm{Sr} /{ }^{86} \mathrm{Sr}$ ) in the ocean. Measurements of past $\mathrm{Sr}$ isotope ratios therefore record a global signal. Other radiogenic isotope systems (e.g., $\mathrm{Pb}, \mathrm{Nd}$ or $\mathrm{Hf}$ ) are often particle reactive, and thus have much shorter residence times and more heterogeneous isotope ratios in seawater. This means that although these systems have the ability to better resolve short timescale changes in continental weathering, their signals are inherently more local and more sensitive to changes in ocean circulation. One issue common to all radiogenic isotope systems is that the source-rock ratios can differ radically as a function of rock age and lithology. This means a change in provenance alone can give the impression of a weathering rate change, or mask or amplify any weathering rate change that does occur.

A further nuance in many radiogenic isotope systems is that specific minerals within a rock often have vastly different isotope ratios. In the $\mathrm{Pb}$ isotope system, some of the radiogenic $\mathrm{Pb}$ isotopes are decay products of ${ }^{235} \mathrm{U}$ and ${ }^{238} \mathrm{U}$. This means that rapidly weathering U-rich accessory minerals may supply highly radiogenic $\mathrm{Pb}$ isotope ratios to river waters, but $\mathrm{Pb}$ released by further weathering of the same parent rock will evolve to less radiogenic $\mathrm{Pb}$ isotope compositions as the slower-weathering, less-U-rich, phases begin to dominate the weathering flux. Foster and Vance (2006) showed that the $\mathrm{Pb}$ isotope ratios of ferromanganese crusts about $1,000 \mathrm{~km}$ off the New England coast (USA) fluctuated between radiogenic and unradiogenic values as the Laurentide ice sheet waxed and waned, interpreted as reflecting the creation and subsequent aging of soils (FIG. 4G). Combined with a published relationship between soil age and weathering rates (Taylor and Blum 1995), Foster and Vance (2006) inferred 
that continental weathering rates in glaciated regions are about $2.5 \mathrm{x}$ higher during interglacials than glacials. However, non-glaciated regions are not affected by this mechanism, and exposure to subaerial weathering of continental shelves during glacials should counteract the decreased weathering in glaciated regions. They suggest that the combined effect was to produce negligible net change at the global scale. As with the proxies above, the story seems to be one of spatially variable weathering responses to G-IG cycling.

\section{Cosmogenic Nuclides}

Cosmogenic nuclides are isotopes created by the interaction of cosmic rays with atomic nuclei. These can be either stable (e.g., ${ }^{3} \mathrm{He},{ }^{21} \mathrm{Ne}$ ) or radioactive (e.g., ${ }^{14} \mathrm{C}$, ${ }^{10} \mathrm{Be}$ ). ${ }^{10} \mathrm{Be}$ is particularly useful. It is produced by spallation reactions with nitrogen or oxygen both in the atmosphere ("meteoric ${ }^{10} \mathrm{Be}^{\text {") }}$ and in the lattices

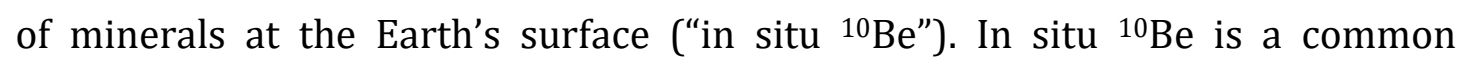
geomorphic and geochronological tool. Schachtman et al. (2019) used the rate of landscape lowering derived from in situ ${ }^{10} \mathrm{Be}$, together with a geochemical assessment of weathering intensity, to estimate G-IG weathering rates for a small catchment in the Oregon Coastal Range (USA). As with the global estimate from $\mathrm{Sr}$ isotopes, there was essentially no resolvable change in weathering rate over the last $30 \mathrm{ka}$. Sample requirements for in situ ${ }^{10} \mathrm{Be}$ are large, whereas meteoric ${ }^{10} \mathrm{Be}$ has the advantage that its production rate is orders of magnitude greater and so sample size requirements are correspondingly smaller. The basic interpretation of meteoric ${ }^{10} \mathrm{Be}$ is relatively simple: it is produced in the atmosphere at a known rate, while ${ }^{9} \mathrm{Be}$ is released as silicate rocks weather. The ratio of meteoric ${ }^{10} \mathrm{Be}$ to stable ${ }^{9} \mathrm{Be}$ is emerging as a powerful and quantitative weathering rate proxy in modern rivers.

Because the contribution of continentally derived ${ }^{10} \mathrm{Be}$ to the open ocean is small (most Be is trapped in the coastal zone), interpreting seawater ${ }^{10} \mathrm{Be} /{ }^{9} \mathrm{Be}$ ratios boils down to dilution of meteoric ${ }^{10} \mathrm{Be}$ raining into the surface ocean with ${ }^{9} \mathrm{Be}$ produced during continental weathering. The ${ }^{10} \mathrm{Be} /{ }^{9} \mathrm{Be}$ ratio therefore varies depending on the size of the ocean basin. The Mediterranean Sea is much more continentally influenced than the Pacific Ocean, for example, and so has a ${ }^{10} \mathrm{Be} /{ }^{9} \mathrm{Be}$ ratio about an order of magnitude lower: $0.1 \times 10^{-7}$ as opposed to $1 \times 10^{-7}$ (von Blanckenburg et al. 2015). This ratio is transferred to authigenic precipitates in marine sediments where it provides an archive of past continental weathering. Ocean ${ }^{10} \mathrm{Be} /{ }^{9} \mathrm{Be}$ ratios have not resolvably changed over the Quaternary G-IG cycles (von Blanckenburg et al. 2015) (FIG. 4I). The actual change that is permissible given the uncertainties is not clear, but the basic implication is that at the scale of ocean basins, silicate weathering rates have not 
varied much across the glacial-interglacial cycles of the Quaternary. As support for this counter-intuitive result, von Blanckenburg et al. (2015) argue that model estimates of river discharge - a first-order control on weathering flux - only varied by a few percent between glacial and interglacial periods. Nevertheless, uncertainties remain: conversion of ${ }^{10} \mathrm{Be} /{ }^{9} \mathrm{Be}$ ratios in ocean sediments to continental weathering rates requires the assumption that a fixed proportion of ${ }^{9} \mathrm{Be}$ is released from primary minerals during weathering and that the trapping of Be in estuaries is constant through time. As future work begins to tackle these issues, we will be able to place plausible constraints on the magnitude of weathering rate change allowed by the near-constant ${ }^{10} \mathrm{Be} /{ }^{9} \mathrm{Be}$ records something that is currently not easy.

\section{A PALAEOWEATHERING SYNTHESIS}

A fascinating suite of mineralogical and geochemical proxies has been applied to address the question of weathering changes across glacial cycles. Although each proxy has its drawbacks, by critically evaluating them together progress can be made and a coherent picture is indeed beginning to appear. At local scales, the available evidence suggests that weathering styles (and so presumably rates) were not constant over glacial-interglacial cycles, albeit with a spatially and temporally heterogeneous response of weathering to climate. Yet despite these regional changes, the emerging picture is that weathering rates, at a global scale, have been broadly constant over the late Quaternary glacial-interglacial cycles. Does this apparent lack of climate control on global weathering rates undermine the weathering feedback as the mechanism responsible for long-term planetary habitability (FIG. 2)? Not necessarily. One way to reconcile the discrepant evidence is that, by coincidence, the exposure of silicates on continental shelves to subaerial weathering is enough to counterbalance any decreases in continental interior weathering. But even if this is the case, other enigmas remain. How is the time-weighted average of global weathering rates under very different climate regimes poised at exactly the right value to maintain long-term mass-balance in a world that swings between them? Is this also just a coincidence, or is it telling us something more profound? Does weathering have a role in limiting the climatic extremes in the cycles? Does silicate weathering and the associated nutrient supply alter ocean chemistry in such a way that it affects biological productivity or the partitioning of carbon between atmosphere and ocean, adding complexity to the feedback? Clearly, there are exciting developments ahead in the coming years. 


\section{ACKNOWLEDGMENTS}

Noah Planavsky, Philip Pogge von Strandmann, Friedhelm von Blanckenburg, and Principal Editor John Eiler are thanked for their thorough and constructive comments on this manuscript.

\section{REFERENCES}

Alizai A and 6 coauthors (2012) Clay mineral variations in Holocene terrestrial sediments from the Indus Basin. Quaternary Research 77: 368-381

Andrews G, Taylor L (2019) Combating climate change through enhanced weathering of silicate rocks on agricultural land. Elements 15: XXX-XXX

Bastian L, Revel M, Bayon G, Dufour A, Vigier N (2017) Abrupt response of chemical weathering to Late Quaternary hydroclimate changes in northeast Africa. Scientific Reports 7, doi: 10.1038/srep44231

Bayon $\mathrm{G}$ and 5 coauthors (2012) Intensifying weathering and land use in Iron Age Central Africa. Science 335: 1219-1222

Bereiter B and 7 coauthors (2015) Revision of the EPICA Dome $\mathrm{C} \mathrm{CO}_{2}$ record from 800 to 600 kyr before present. Geophysical Research Letters 42: 542-549

Berner RA, Caldeira K (1997) The need for mass balance and feedback in the geochemical carbon cycle. Geology 25: 955-956

Biscaye PE (1965) Mineralogy and sedimentation of recent deep-sea clay in the Atlantic Ocean and adjacent seas and oceans. Geological Society of America Bulletin 76: 803-832

Bouchez J, von Blanckenburg F, Schuessler JA (2013) Modeling novel stable isotope ratios in the weathering zone. American Journal of Science 313: 267-308

Dellinger M and 8 coauthors (2015) Riverine Li isotope fractionation in the Amazon River basin controlled by the weathering regimes. Geochimica et Cosmochimica Acta 164: 71-93

Dosseto A and 5 coauthors (2015) Rapid response of silicate weathering rates to climate change in the Himalaya. Geochemical Perspectives Letters 1: 1019

Ehlers J, Gibbard PL (2003) Extent and chronology of glaciations. Quaternary Science Reviews 22: 1561-1568

Foster GL, Royer DL, Lunt DJ (2017) Future climate forcing potentially without precedent in the last 420 million years. Nature Communications 8, doi: 10.1038/ncomms14845

Foster GL, Vance D (2006) Negligible glacial-interglacial variation in continental chemical weathering rates. Nature 444: 918-921

Frings PJ, Clymans W, Fontorbe G, De La Rocha CL, Conley DJ (2016) The continental Si cycle and its impact on the ocean Si isotope budget. Chemical Geology 425: 12-36 
Gaillardet J, Dupré B, Louvat P, Allègre CJ (1999) Global silicate weathering and $\mathrm{CO}_{2}$ consumption rates deduced from the chemistry of large rivers. Chemical Geology 159: 3-30

Kasting JF (2019) The goldilocks planet? How silicate weathering maintains Earth "just right". Elements 15: XXX-XXX

Lupker M, France-Lanord C, Galy V, Lavé J, Kudrass H (2013) Increasing chemical weathering in the Himalayan system since the Last Glacial Maximum. Earth and Planetary Science Letters 365: 243-252

Maher K, Chamberlain CP (2014) Hydrologic regulation of chemical weathering and the geologic carbon cycle. Science 343: 1502-1504

Mokadem $\mathrm{F}$ and 5 coauthors (2015) High-precision radiogenic strontium isotope measurements of the modern and glacial ocean: limits on glacialinterglacial variations in continental weathering. Earth and Planetary Science Letters 415: 111-120

Pogge von Strandmann PAE and 5 coauthors (2017) Lithium isotopes in speleothems: temperature-controlled variation in silicate weathering during glacial cycles. Earth and Planetary Science Letters 469: 64-74

Porder S (2019) How plants enhance weathering and how weathering is important to plants. Elements 15: XXX-XXX

Roberts J and 8 coauthors (2018) Lithium isotopic composition of benthic foraminifera: a new proxy for paleo-pH reconstruction. Geochimica et Cosmochimica Acta 236: 336-350

Schachtman NS, Roering JJ, Marshall JA, Gavin DG, Granger DE (2019) The interplay between physical and chemical erosion over glacial-interglacial cycles. Geology 47: 613-616

Taylor A, Blum JD (1995) Relation between soil age and silicate weathering rates determined from the chemical evolution of a glacial chronosequence. Geology 23: 979-982

Thiry M (2000) Palaeoclimatic interpretation of clay minerals in marine deposits: an outlook from the continental origin. Earth-Science Reviews 49: 201-221

von Blanckenburg F, Bouchez J, Ibarra DE, Maher K (2015) Stable runoff and weathering fluxes into the oceans over Quaternary climate cycles. Nature Geoscience 8: 538-542

Walker JCG, Hays PB, Kasting JF (1981) A negative feedback mechanism for the long-term stabilization of Earth's surface temperature. Journal of Geophysical Research: Oceans 86: 9776-9782

Wan S and 14 coauthors (2017) Enhanced silicate weathering of tropical shelf sediments exposed during glacial lowstands: a sink for atmospheric $\mathrm{CO}_{2}$. Geochimica et Cosmochimica Acta 200: 123-144

Zeebe RE, Caldeira K (2008) Close mass balance of long-term carbon fluxes from ice-core $\mathrm{CO}_{2}$ and ocean chemistry records. Nature Geoscience 1: 312-315 
Zhao S and 5 coauthors (2018) Responses of the East Asian summer monsoon in the low-latitude South China Sea to high-latitude millennial-scale climatic changes during the last glaciation: evidence from a high-resolution clay mineralogical record. Paleoceanography and Paleoclimatology 33: 745765

\section{FIGURE CAPTIONS}

FIGURE 1 Schematic of the silicate weathering feedback. Reaction with silicate minerals (idealised here as wollastonite, $\mathrm{CaSiO}_{3}$ ) converts $\mathrm{CO}_{2}$ to bicarbonate ions that can later be precipitated as carbonate minerals in the ocean. Weathering rates should be positively correlated with temperature and rainfall and so provide the stabilising (negative) feedback on Earth's surface temperatures shown in the inset feedback loop.

FIGURE 2 Reconstructed atmospheric $\mathrm{CO}_{2}$ during the Phanerozoic, as compiled by Foster et al. (2017), and the deviation in atmospheric $\mathrm{CO}_{2}$ from an average lateQuaternary value expected for $\pm 1 \%, 25 \%, 50 \%$ and $100 \%$ imbalances between silicate weathering and solid Earth degassing (held constant at $7 \times 10^{12} \mathrm{~mol} \mathrm{y}^{-1}$, and under the assumption of invariant carbon partitioning between Earth's surface pools). ppmv = parts per million by volume. Mauna Loa is the volcano in Hawai'i (USA). FIGURE INSPIRED BY FoSTER ET AL. (2017) AND BERNER AND CALDEIRA (1997).

FIGURE 3 The world at the last glacial maximum $(\sim 21,000$ years ago $)$ differed from today. Ice-sheets covered large parts of northern America and Europe and vast areas of continental shelf were exposed. Palaeoweathering reconstructions, detailed in the main text, from different regions and different proxies give different results. ICE-SHEET EXTENT FROM EHLERS AND GIBBARD (2003), BATHYMETRY FROM ETOPO1 DATA, AND SEA-ICE EXTENT FROM THE PALEOCLIMATE MOdELling INTERCOMPARISON PROJECT (PMIP).

FIGURE 4 Compilation of glacial-interglacial palaeoweathering proxy data mentioned in the main text and in FIGURE 2. (A) Kaolinite concentration in marine core MD12-3434, from 3,000 m water depth in the South China Sea. From ZHAO ET AL. (2018). (B) Smectite contribution to clay assemblage in International Ocean Drilling Program Leg 184 site 1144, 2,000 m water depth in the South China Sea. From WAN ET AL. (2017). (C) Bay of Bengal detrital sediment K/Si ratios. From LuPKer ET AL. (2013). (D) Congo River Delta detrital sediment K/Al ratios. From BAyON ET AL. (2012). (E) Near-constant marine $\delta^{7} \mathrm{Li}$ in Pacific Ocean foraminifera and more variable $\delta^{7} \mathrm{Li}$ in an Israeli speleothem. FROM RoBERTS ET AL. (2018) AND Pogge von Strandmann et AL. (2017), ReSPectively. (F) Increasing clay lithium 
isotope ratios in Himalayan terraces and decreasing in the Nile River Delta. From Dosseto ET AL. (2015) AND BASTIAn ET AL. (2017), RESPECTIVEly. (G) Lead isotope ratios in North Atlantic Ocean ferromanganese crusts. From Foster AND VANCE (2006). (H) Constant Sr isotope ratios from Indian Ocean foraminifera. From MoKADEM ET AL. (2015). (I) Constant ${ }^{10} \mathrm{Be} /{ }^{9} \mathrm{Be}$ in marine authigenic sediments from the Mediterranean Sea. From von Blanckenburg et AL. (2015). (J) Atmospheric $p \mathrm{CO}_{2}$ derived from Antarctic ice cores as a proxy for global climate. From BEREITER ET AL. (2015). 


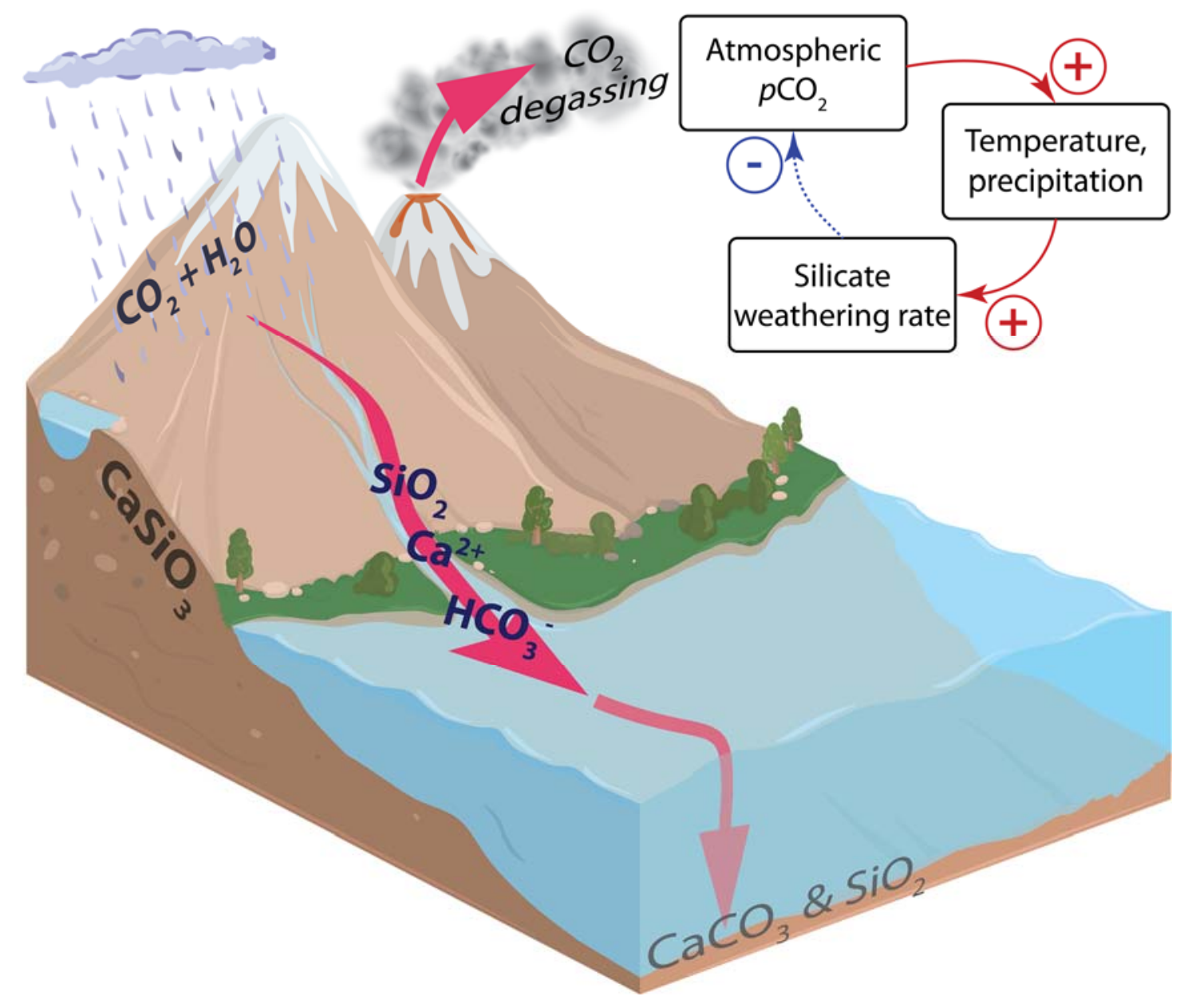




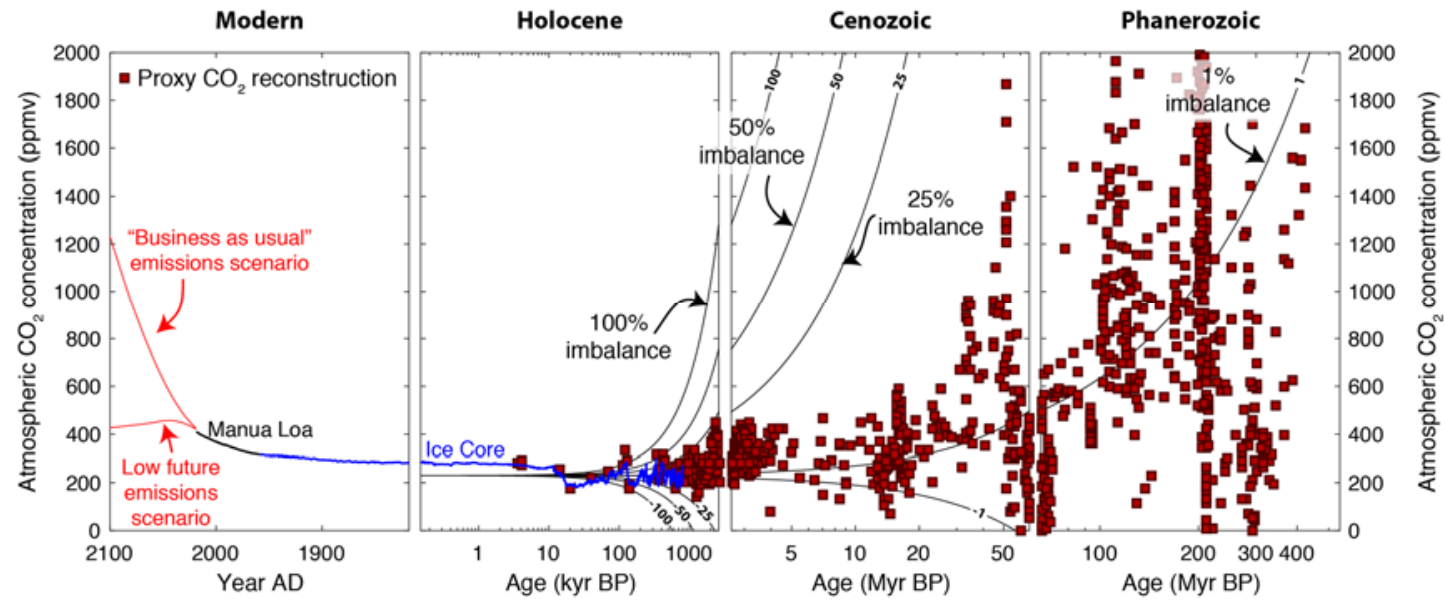




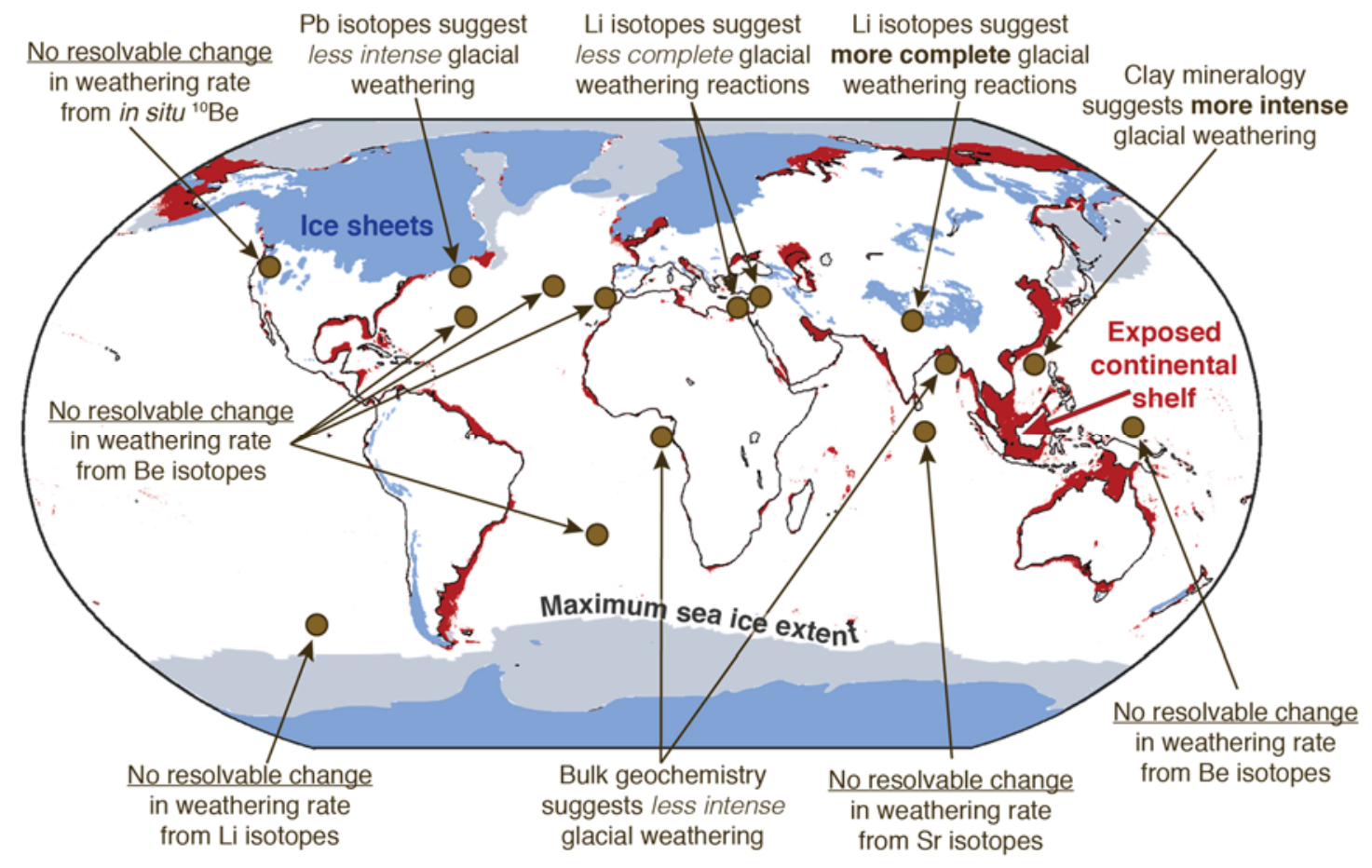




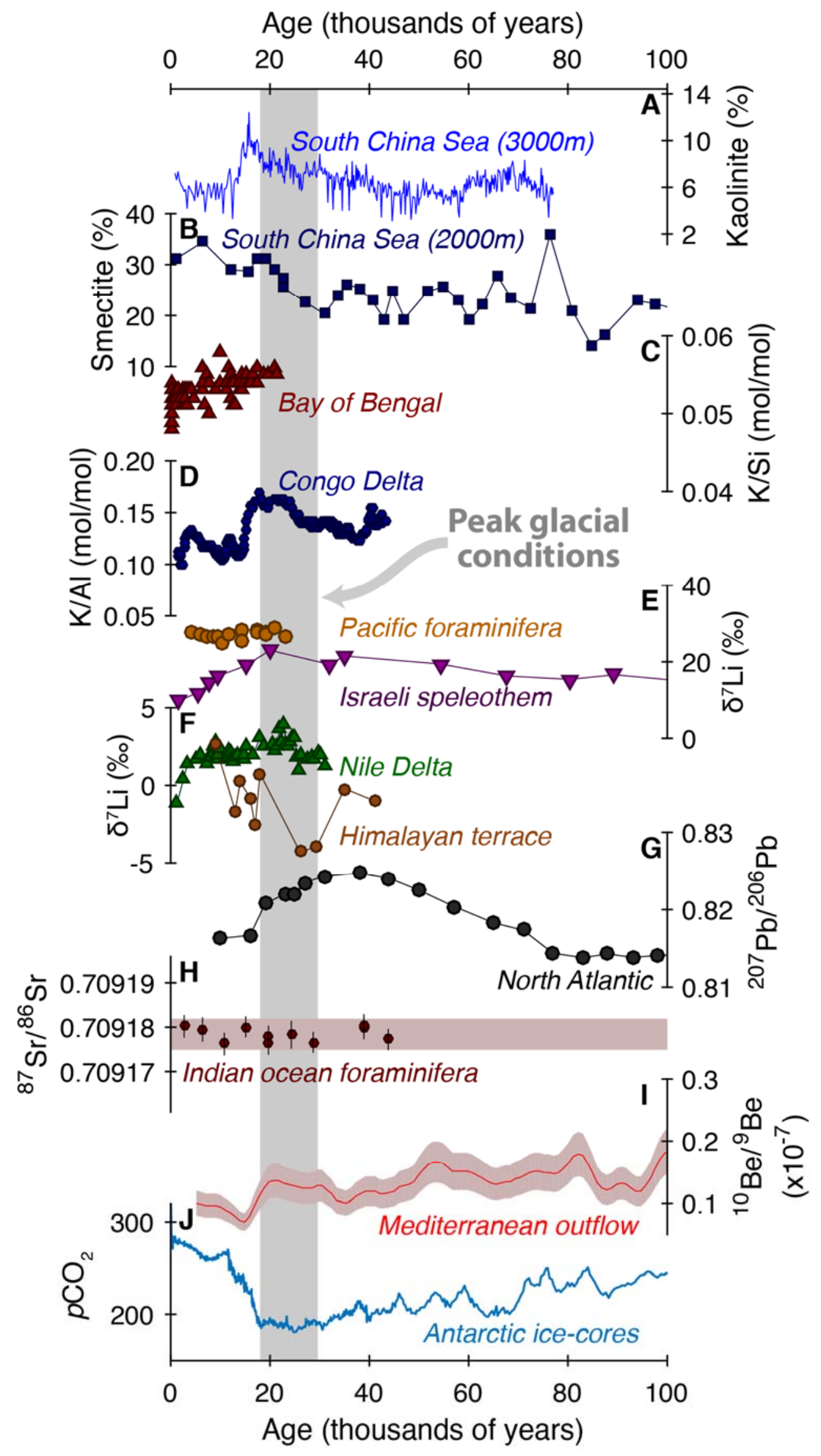

